ESTUDIO

\title{
UNA NOTA SOBRE LA TEORÍA ESPACIAL DEL VOTO*
}

\author{
Claudio A. Bonilla y Leonardo A. Gatica
}

La competencia política en años eleccionarios muchas veces lleva a las coaliciones gobernantes a implementar políticas públicas que van en contra de la eficiencia económica, y que no pueden ser explicadas con el paradigma del accionar racional y benevolente del gobierno. La Teoría Espacial del Voto (TEV), por el contrario, descarta el actuar benevolente del gobierno y supone que su objetivo (y el de todos los actores políticos involucrados en una elección) es complacer la mayor parte del electorado posible con las posiciones que adopte, para así aumentar la posibilidad de ganar adherentes y elecciones. La siguiente nota presenta una breve discusión sobre el desarrollo de la economía política neoclásica y los principales aportes que la TEV, como principal vertiente dentro de ella, ha hecho al entendimiento del accionar de los gobiernos, especialmente en las cercanías a una elección.

Claudio A. Bonilla. Ph.D. en Economía de la Universidad de Texas, Austin e Ingeniero en Información y Control de Gestión de la Universidad de Chile. Actualmente se desempeña como profesor asistente del Departamento de Sistemas de Información y del Departamento de Administración de la Universidad de Chile.

Leonardo A. Gatica. Ph.D. en Economía de la Universidad de Texas, Austin. Actualmente se desempeña como profesor asistente en el Departamento de Economía de la Universidad de Guadalajara.

* Agradecemos a Mel Hinich por las largas conversaciones que hemos sostenido sobre el tema y por sus útiles comentarios. Agradecemos también las observaciones y comentarios de Patricia Murrieta, Cristián Larroulet y dos árbitros anónimos. Las ideas y opiniones expresadas en este artículo son únicamente responsabilidad de los autores. 


\section{www.cepchile.cl}

\section{Introducción}

巨化 racionales toman decisiones económicas tratando de maximizar sus funciones objetivos (generalmente pensamos en utilidad) sujetos a restricciones de recursos. Usualmente estudiamos las reglas de decisión óptimas que representan el comportamiento de los agentes económicos involucrados en un modelo.

Cuando incluimos al sector gobierno en el análisis ${ }^{1}$, generalmente estudiamos cuáles son las mejores políticas económicas que el gobierno puede aplicar. Mejores desde una perspectiva positiva, esto es, políticas económicas que maximicen el bienestar de la sociedad en su conjunto y al mismo tiempo minimicen las pérdidas de eficiencia económica producto del efecto que el actuar del gobierno tiene sobre los agentes. Ejemplos de este tipo de análisis son las reglas óptimas de impuestos, las regulaciones de mercados donde no hay suficiente competencia o las reglas óptimas de política monetaria.

El análisis anterior asume que el gobierno busca lo mejor para sus ciudadanos y aplica la política económica para acercarse a un equilibrio que representa el óptimo social. Sin embargo, esta manera de mirar el actuar del gobierno es, hasta cierto punto, limitada. Esta forma de pensar el gobierno no provee una buena explicación de su actuar al acercarse un período eleccionario. Reconocemos que es la forma usual de pensar el gobierno y sus políticas económicas y, de hecho, debería ser siempre la forma de hacer políticas públicas. Sin embargo, lamentablemente en la práctica no es siempre así. No es difícil encontrar episodios cercanos en nuestra coyuntura reciente, donde algunas políticas públicas fueron anunciadas y en algunos casos implementadas y que, claramente, estaban lejos de ser las mejores para la economía. Para dar un ejemplo cercano de lo anterior, basta recordar la discusión sobre la reforma laboral que tuvo lugar en Chile antes de la elección de diciembre de 1999.

Dado lo anterior, podría ser de utilidad suponer que a veces el gobierno no es necesariamente benevolente (al menos para analizar los períodos pre-eleccionarios), es decir, que no se preocupa siempre por implementar políticas públicas que son óptimas desde una perspectiva económica. Podríamos pensar que en ciertos períodos el gobierno tiene un objetivo distinto al de aplicar buenas políticas públicas para la gente, más concreta-

${ }^{1}$ En campos como la macroeconomía o el estudio de las finanzas públicas, por ejemplo. 
mente, podríamos pensar en un modelo económico (racional) en el cual el gobierno se preocupa sólo por maximizar votos y mantenerse en el poder ${ }^{2}$.

Si éste fuera el caso, ya no es tan sencillo analizar las políticas públicas bajo el prisma de la teoría puramente económica, por la simple razón de que no es optimalidad el criterio generador de las decisiones públicas. Afortunadamente, a partir de los años sesenta y con mayor fuerza en los ochenta, se comenzó a estudiar de manera más seria la economía política. Esta teoría, relativamente joven e imperfecta como todo nuevo paradigma, proporciona explicaciones alternativas del actuar del gobierno a las clásicas explicaciones de la teoría económica, especialmente en períodos en los que la optimalidad económica es sobrepasada por el accionar político de quienes gobiernan. Y es precisamente la teoría espacial del voto (TEV), que pasamos a revisar a continuación, la principal vertiente en economía política que nos ayuda a entender políticas públicas que pueden estar tan alejadas de la optimalidad de Pareto.

El resto del artículo está estructurado de la siguiente manera. La sección dos contiene una breve discusión del surgimiento de la economía política en la literatura. Enseguida se introduce la teoría espacial del voto (TEV) y se presentan los aportes más importantes que esta escuela ha hecho al entendimiento racional de la política y de la interacción entre economía y política. La cuarta sección contiene las principales conclusiones del trabajo.

\section{El surgimiento de la economía política neoclásica}

Desde los inicios de la ciencia económica, el estudio de la política y el de la economía han estado fuertemente relacionados. Nombres como Smith, Ricardo, Marx o Mill están vinculados no sólo con el estudio de los fenómenos económicos sino también del Estado. Fueron estos filósofos y estudiosos del comportamiento económico y social quienes realizaron las primeras sistematizaciones sobre el funcionamiento de la economía y el papel que el Estado desempeña dentro del fenómeno económico. De allí que con estos pensadores la disciplina tomara la forma de lo que se conoce como Economía Política.

Con la publicación de La Teoría de la Economía Política de Jevons en 1871 y su incorporación del análisis matemático a las ideas utilitaristas, comenzó el desarrollo del análisis microeconómico marginalista. Éste fue el inicio de un nuevo programa de investigación que construyó un individualismo metodológico como fundamento, y que evolucionó hacia lo que hoy

\footnotetext{
${ }^{2} \mathrm{O}$ bien que la coalición a la que pertenece se mantenga en el poder.
} 
conocemos como la teoría de la elección racional, lo que para efecto de nuestro artículo llamamos programa o escuela neoclásica. En la segunda mitad del siglo veinte la escuela neoclásica incorporó el análisis económicopolítico en su programa de investigación; más aún, incursionó en el análisis del fenómeno puramente político utilizando sus fundamentos metodológicos y sus técnicas de análisis económico, para convertirse en una importante corriente dentro de la ciencia política, no sin provocar discusiones y críticas que continúan hasta nuestros días ${ }^{3}$.

Los fundamentos metodológicos de este programa son básicamente dos. El primero es el supuesto de que la interacción de agentes sociales individuales determina los resultados finales. El segundo fundamento supone que estos agentes individuales son racionales en el sentido de mantener objetivos claros que tratan de lograr, para lo cual se forman expectativas sobre las acciones de los otros agentes y actúan considerando el contexto en el que se desenvuelven. Así, este programa de la ciencia económica abstrae los problemas económicos de los mecanismos de decisión implementados por agentes racionales individuales que buscan maximizar su utilidad y que en este proceso interactúan con otros agentes y enfrentan restricciones institucionales y de recursos. La solución del problema se reduce a las reglas de decisión óptimas que representan el comportamiento de los agentes involucrados; son estas reglas el objeto de estudio en el programa neoclásico.

De lo anterior se deduce que el supuesto de neutralidad y benevolencia del gobierno conlleva a un análisis más normativo que positivo, $\mathrm{y}$ dado que se reconoce que una parte de la problemática económica tiene un componente político, tal y como lo plantearon los economistas clásicos, es importante considerar la racionalidad tanto del gobierno como de los agentes sociales con los que interactúa para poder comprender tal problemática y encontrar soluciones adecuadas. A partir de Kramer (1977) y Nordhaus (1975) el programa neoclásico incorporó la racionalidad del gobierno para explicar y analizar el diseño y la implementación de la política económica. Los desarrollos a partir de estos trabajos seminales conforman lo que se conoce como teoría del ciclo económico-político. La incorporación del concepto de votante mediano de Black (1958) en la teoría macroeconómica dio

${ }^{3}$ Sobre la influencia que ha tenido la teoría de elección racional en la ciencia política véanse por ejemplo Riker (1990), Miller (1997), Ostrom (1998), Levi (1997), Amadae y Bueno de Mesquita (1999) y Munck (2001). Algunas de las discusiones más recientes sobre el uso de elección racional después del conocido argumento de Green y Shapiro (1994) —quienes sostienen que la aplicación del método de la elección racional en ciencias políticas no ha producido buenas explicaciones empíricas de lo que realmente sucede en la política - son Friedman (1996), Bates et al. (1998 y 2000), Elster (2000), Wagner (2001), Lichbagh (2002) y Weyland (2002). 
pie para el análisis de la política fiscal, los procesos redistributivos, el crecimiento económico, la reforma económica y la coordinación de políticas internacionales ${ }^{4}$. Por otro lado, los trabajos de Olson (1971) y Becker (1983, 1985) fueron la pauta para la aparición de un considerable número de artículos sobre grupos de interés y su impacto en las políticas públicas y en el comercio internacional $^{5}$.

En 1937 Coase planteó por primera vez que los costos de transacción varían dependiendo de la organización institucional que los maneje o regule. Coase $(1937,1960)$ no aplicó sus ideas sobre costos de transacción, externalidades y costo social al análisis de las instituciones políticas, sin embargo fueron retomadas en los trabajos seminales de Buchanan y Tullock (1962) y de North (1981) que, bajo los axiomas metodológicos de la teoría de elección racional, contribuyeron profundamente al desarrollo del análisis de diseño institucional y del llamado "nuevo institucionalismo"6 respectivamente. Es a partir principalmente del trabajo de Douglas North ${ }^{7}$ que el pro-

${ }^{4}$ Una referencia general sobre política macroeconómica y economía política es Persson y Tabellini (1999) así como Tabellini y Alesina (1990), Persson, Roland y Tabellini (1998) y Svensson (1997) sobre política fiscal y finanzas públicas. En cuanto al problema de redistribución, los primeros modelos se deben a Romer (1975), Roberts (1977) y Meltzer y Richard (1981). Para discusiones subsecuentes sobre distribución, desigualdad y crecimiento véanse Alesina y Rodrik (1994), J. Svensson (1999), Persson y Tabellini (1992a, 1994), Piketty (1995), Roemer y Woojin (1999), Saint-Paul y Verdier (1993), Krusell, Quadrini y Rios Rull (1997), Krusell y Rios Rull (1999). Sobre reforma económica una referencia general es Sturzenegger y Tommasi (1998). En cuanto al tema de coordinación Fisher (1988), Chang (1990), Tabellini (1990), Staiger (1995), Persson y Tabellini (1992b, 1995, 1996), Dixit (1999), Dixit, Grossman y Helpman (1997) y L. Svensson(1999) son algunos ejemplos.

${ }^{5}$ Véanse por ejemplo Dixit (1996, 1997), Persson (1998), Saint-Paul (1999) y Grossman y Helpman (1996, 2002a). En cuanto a la incidencia de los grupos de interés en la política económica internacional, véanse Rodrik (1995), Rodrik y van Ypersele (1999), Grossman y Helpman (1995, 2002b) y Svensson (1996).

${ }^{6}$ Hall y Taylor (1996) observan tres tipos de Nuevo Institucionalismo: institucionalismo histórico, sociológico y de elección racional. A su vez, dentro de este último tipo de nuevo institucionalismo se han reconocido diferentes vertientes. Bardhan (1989) distingue dos corrientes; una basada en los problemas de información asimétrica introducidos por Akerlof (1970) y otra basada en los costos de transacción y derechos de propiedad que retoma las ideas de Coase. Derivada de esta última corriente, Leys (1996) reconoce una tercera más involucrada con los procesos políticos donde sitúa a Bates (1981) y North (1990). Esta última ha sido llamada Nueva Economía Política.

${ }^{7}$ Durante los setenta se dieron una serie de desarrollos que tomaban el marco institucional como variable relevante para explicar diversos fenómenos económicos, sin embargo North es el probablemente el exponente más reconocido en este campo. Su trabajo (principalmente North 1981, 1990, Davis y North 1971, North y Thomas 1973 y North y Weingast 1989) ha sido de gran influencia, pero es con Structure and 
grama neoclásico reconoce la importancia que las instituciones tienen en la creación de incentivos y la imposición de restricciones para conformar contextos que limitan el comportamiento racional individual de diversas formas, dando lugar a la existencia de equilibrios múltiples (North, 1990) y, por lo tanto, a la posible existencia de diversas formas de manejar y resolver los problemas de acción colectiva más allá del mercado y del Estado ${ }^{8}$, en particular frente a la necesidad de enfrentar riesgos en presencia de mercados incompletos ${ }^{9}$. Así, el programa neoclásico incorporó factores de carácter político en la explicación de los procesos de desarrollo y crecimiento económico tanto en análisis de carácter macro como en análisis micro.

Durante los noventa, el nuevo institucionalismo y su impacto en los estudios de historia y desarrollo económico, influenciaron de manera importante el análisis político de países en desarrollo y los análisis de política comparada. Sin embargo, el uso del institucionalismo basado en la teoría de elección racional en la ciencia política se inició un poco antes con algunos estudios sobre procesos políticos y sociales en países en desarrollo ${ }^{10} \mathrm{y}$ con el análisis del comportamiento legislativo en el Congreso Norteamerica-

Change in Economic History (1981) que intenta construir una teoría general del desarrollo y crecimiento de las naciones a partir de la perspectiva neoclásica y la introducción de las instituciones como variable explicativa. A la par de la teoría de North (1981), Gilpin (1981) y Olson (1982) propusieron también teorías generales sobre desarrollo y crecimiento económico (para una crítica de estas teorías, véase Rogowski 1983). Al libro de Olson (1982) le sucedió el argumento más general sobre la tendencia decreciente del crecimiento económico de Kennedy (1987). Sin embargo ninguna de las teorías de Gilpin, Olson o Kennedy son convincentes y han tenido poca influencia en trabajos subsecuentes. En su último libro, publicado después de su muerte, Olson (2000) trató de determinar condiciones aun más generales, suficientes y necesarias para garantizar el crecimiento económico. Más recientemente Shofield (2003) hace un intento por desarrollar la teoría de Olson (2000) y busca determinar el mecanismo de relación entre crecimiento y libertad política.

${ }^{8}$ La exposición de Elinor Ostrom (1990) sobre el tema es probablemente la más notable desde la ciencia política. La existencia de fallas de los mercados y del Estado es el principal argumento para explicar las diferentes trayectorias de desarrollo. Stiglitz (1986), Toye (1993) y Khan (1995) hacen un recuento de estos argumentos.

${ }^{9}$ Un ejemplo de la conformación de instituciones en ausencia de un Estado eficiente es el trabajo de Popkin (1979). Otros argumentos sobre el surgimiento de instituciones frente a la existencia de mercados incompletos son Posner (1980), Cohen (1981), Binswagner y Rosenzweig (1984), Bates (1989, 1990) y Montiel (1993). En los últimos años la teoría neoclásica del desarrollo económico ha incorporado de forma fundamental la presencia de mercados incompletos frente a problemas de información y coordinación (véanse por ejemplo Ray, 1998, y Bardham y Urdy, 1999).

${ }^{10}$ Los trabajos seminales son el de Bates (1981) y el ya citado de Popkin (1979). 
no ${ }^{11}$. Dos de los primeros trabajos más prominentes en el análisis de países en desarrollo son los de Popkin (1979) y Bates (1981). En su trabajo clásico, Popkin (1979) analizó, desde la perspectiva de la teoría de la elección racional y el comportamiento microeconómico, el uso de instituciones informales y formales para explicar el comportamiento revolucionario de los campesinos vietnamitas. Bates (1981) por su parte trata de explicar la crisis de la agricultura en África empleando la teoría de la elección racional. Estos trabajos seminales fueron los primeros en aplicar explícitamente la teoría de elección racional en el análisis político de países en desarrollo ${ }^{12}$. Aun cuando estos trabajos tuvieron algún impacto en la ciencia política durante los siguientes años, no tuvieron la misma influencia que los análisis sobre procesos legislativos.

Probablemente debido a que el análisis de instituciones formales es más claro y explícito que el de instituciones informales (además del menor interés que existe en EE.UU. sobre ciertas regiones), los primeros trabajos sobre procesos legislativos basados en elección racional tuvieron un fuerte impacto e incentivaron la aparición de una gran cantidad de literatura. La introducción del análisis institucional en el estudio de los procesos legislativos permitió explicar la inconsistencia de los modelos teóricos de elección racional con la estabilidad de los resultados en el Congreso y otros órganos de decisión colectiva ${ }^{13}$. Posteriormente se iniciaron análisis sobre comportamiento partidista ${ }^{14}$ y más recientemente el trabajo de Cox (1997) ha tenido

${ }^{11}$ En su artículo seminal, Riker (1980) planteó el problema de inestabilidad y de intransitividad de las votaciones por mayoría y la necesidad de considerar las instituciones para comprender la estabilidad que en el corto plazo presentan ciertos procesos democráticos de elección social. Otros artículos que analizan este problema son Ferejohn y Fiorina (1975) y McKelvey (1976).

${ }^{12}$ Durante los setenta y los ochenta se dio una fuerte discusión sobre producción agrícola, desarrollo y derechos de propiedad desde la economía neoclásica y el institucionalismo. Algunos de los ejemplos más destacados son Ruttan (1979a, 1979b, 1980), Posner (1981), Davis y North (1971), North y Thomas (1973), Feeney (1982, 1988), Guttman (1978, 1980) y los libros editados por Binswagner y Ruttan (1978), Hayami y Ruttan (1971) y Russell y Nicholson (1981). Sin embargo, los textos de Popkin y Bates fueron los más explícitos en el uso de la teoría de elección racional para el estudio de comunidades rurales y fenómenos políticos. Para una revisión general de la literatura sobre esta área de investigación, véase Bates (1990).

${ }^{13}$ Los trabajos seminales de Shepsle $(1979,1986,1989)$, Moe (1984) y Weingast y Marshall (1988) argumentan que las instituciones resuelven los problemas de intransitividad y de acción colectiva al proporcionar reglas que disminuyen los costos de transacción y generan estabilidad en las decisiones legislativas.

${ }^{14}$ La literatura sobre partidos desde la perspectiva institucional y de elección racional ya es sumamente amplia. Para una revisión general de la literatura véase Stokes (2001). Algunos otros ejemplos son Przeworski y Sprague (1986), Mair (1990), Kitschelt (1989, 1994), Iversen (1994b), Kalyvas (1996) y Hug (2001). 
una importante acogida al retomar el argumento de Duverger ([1951]1972) sobre votación estratégica e incorporar la teoría de elección racional al estudio de los sistemas electorales ${ }^{15}$. Estos análisis tuvieron una importante influencia principalmente en los estudios de política comparada. Sin embargo a la par del análisis institucional en estos estudios se incorporó una herramienta metodológica más, basada también en los principios de la elección racional pero en ambientes de interacción estratégica: la teoría de juegos.

Las primeras aplicaciones de teoría de juegos en ciencia política fueron en temas de relaciones internacionales debido a que el número de actores en este tipo de problemas es pequeño y la interacción estratégica es evidente. Posteriormente la teoría de juegos se incorporó en otras áreas de la ciencia política como los estudios legislativos y electorales así como en el estudio de la burocracia. Particularmente durante los años noventa el área de política comparada se vio fuertemente influenciada por la teoría de juegos, y esta última continúa siendo una herramienta ampliamente utilizada que, en la gran mayoría de los casos, se combina con aproximaciones institucionalistas ${ }^{16}$. En general, la aplicación de la teoría de juegos y el enfoque

${ }^{15}$ Otros análisis sobre sistemas electorales son Cox (1987, 1990a), Chhibber y Kollman (1998), Boix (1999), Carey y Shugart (1995), Shugart y Carey (1992), Lijphart (1994), Taagapera y Shugart (1989), Kostadinova (2002), Benoit (2004) y Moser (2002).

${ }^{16}$ Véase por ejemplo O’Neill (1992) para una revisión de la literatura sobre conflictos internacionales y guerra. Otros ejemplos importantes de análisis sobre crisis internacionales son los de Kilgour y Zagare (1991), Wagner (1991), Fearon (1994), Bueno de Mesquita y Lalman (1992). Snidal (1985) revisa también la literatura sobre relaciones internacionales y otros ejemplos en esta área son Niou y Ordeshook (1989, 1990), Wagner (1983, 1986), Powell (1991), Putnam (1988) e Iida (1993). En cuanto a los procesos legislativos basados en la estructura constitucional norteamericana existe ya un enorme número de artículos; Shepsle y Weingast (1994) hacen un buen resumen sobre la literatura existente. Sobre la relación entre la estructura institucional y los resultados legislativos, Shepsle (1979) es el artículo seminal, al que le sigue Shepsle y Weingast (1987). Sobre problemas de información asimétrica en el Congreso, véanse por ejemplo Krehbiel (1991), Gilligan y Krehbiel (1987, 1989, 1990); Ainsworth y Sened (1993) y Austen-Smith (1993) construyen argumentos sobre la relación entre información y cabildeo. Austen-Smith (1990) y Austen-Smith y Riker (1987, 1990) desarrollaron modelos de señalización y negociación en el Congreso. Sobre procesos electorales Coughlin (1990) y Aldrich (1993) revisan la literatura sobre elecciones y modelos formales. Sobre participación electoral véanse por ejemplo Ledyard (1984) y Palfrey y Rosenthal (1985). La competencia electoral y partidista se ha modelado principalmente en contextos espaciales; sobre este tema véanse Enelow y Hinich (1984, 1990), Hinich y Munger (1997), Roemer (2001), Ordeshook (1997) y Shofield (1997) como referencias generales. El primer desarrollo de votación retrospectiva fue el de Ferejohn (1986) y a éste le siguió el de Austen-Smith y Banks (1989). Sobre 
institucional se desarrolló en estudios enfocados a problemáticas de países desarrollados. No es sino con la tercera ola de democratización que el interés por las sociedades en desarrollo se renovó y, con ello, se incentivó la aplicación de estos instrumentos metodológicos en el estudio de estos países.

Hacia fines de los años cincuenta, Downs (1957) y Black (1958) retomaron una de las ideas fundamentales de Hotelling (1929), e iniciaron el análisis específico del tema político desde la perspectiva de la economía neoclásica. A estas aportaciones se adhirieron los planteamientos sobre los problemas de agregación de preferencias y de elección social de Arrow (1951) y los desarrollos en la teoría de juegos que siguieron a la publicación del libro seminal de Von Neumann y Morgenstern (1944). Junto con los posteriores aportes de Olson (1971) para el análisis de la acción colectiva, así como los de Buchanan y Tullock (1962) y Douglas North (1981), le proporcionaron a la escuela neoclásica los fundamentos para el desarrollo del análisis político.

En consecuencia, el surgimiento de la economía política neoclásica se deriva de distintas fuentes que confluyen en el uso del paradigma de la racionalidad en el actuar, no sólo de los agentes "privados", sino también de los actores que detentan el poder y cuya esfera de decisiones afectan lo público. Además, distintas escuelas especializadas dentro de la economía política neoclásica se han desarrollado a partir de las ideas seminales de los diversos autores ${ }^{17}$, cada una con características propias que dan para un volumen completo. Sin embargo, la escuela de la teoría espacial del

contribuciones de campaña y competencia electoral véanse por ejemplo Snyder (1990) y Bonilla (2004). Stokes (1999) resume los desarrollos sobre partidos políticos y competencia electoral. Sobre sistemas de partidos múltiples, Laver y Shofield (1990) es una introducción sencilla y buena sobre el tema. Otros desarrollos sobre partidos múltiples son Austen-Smith y Banks (1990), Laver y Shepsle (1990), Baron (1993) y Greenberg y Shepsle (1987), y Shepsle y Cohen (1990). En cuanto a estudios de política comparada Weingast (1997) hace un recuento de estos análisis. Como hemos señalado, en su mayoría esta literatura se aboca a los países desarrollados. Véanse por ejemplo Palfrey (1989) y Cox (1990a) sobre reglas electorales y comportamiento partidista. Wallerstein $(1989,1990)$ ha realizado estudios sobre corporativismo y sindicalismo en países desarrollados. Para un análisis sobre el efecto de las reglas legislativas sobre procesos de negociación en el congreso, véase Huber (1992). Tsebelis (1990, 2002) utiliza la teoría de juegos para construir modelos que expliquen el comportamiento parlamentario. En cuanto a procesos de democratización y reforma política véase por ejemplo Przeworski (1991). Argumentos importantes sobre nacionalismo y conflictos étnicos son, por ejemplo, los de Laitin (1993, 1998, 1999).

${ }^{17}$ Ejemplos son la escuela de los ciclos político-económicos, la escuela de la teoría de juegos aplicada a la ciencia política, la escuela de la teoría espacial del voto (TEV), la escuela de los ciclos presupuestarios, etc. 
voto (TEV) destaca entre todas por ser quizás la más antigua y cuyos resultados forman parte del bagaje mínimo que toda persona interesada en estudiar la interacción entre el Estado y el mercado o lo público y lo privado debiese conocer.

\section{La teoría espacial del voto (TEV)}

La escuela espacial (o escuela Downsiana) aplica el análisis microeconómico clásico al estudio de las elecciones a través del uso del modelo de competencia espacial. Son varios los temas que pueden ser analizados bajo el prisma de la TEV, por ejemplo la manera cómo las coaliciones gobernantes tratan de retener el poder, cómo ciertas características de los candidatos afectan los resultados electorales, o cómo la incertidumbre es manejada en las votaciones.

Los inicios de la TEV

El primero en sugerir el uso de un modelo espacial para el estudio del comportamiento competitivo de agentes económicos fue Hotelling (1929). Si bien este primer modelo no pretendía analizar comportamiento político alguno, es el punto de partida para el estudio formal de la competencia electoral. Hotelling estaba interesado en estudiar la razón por la cual es usual encontrar dos empresas que compiten entre sí localizadas geográficamente muy cerca una de la otra. Las estaciones de bencina, por ejemplo, están generalmente localizadas en las esquinas opuestas de la misma intersección o a una distancia reducida en la misma cuadra, las multitiendas están usualmente ubicadas en el mismo complejo comercial, una larga avenida contiene en una o dos cuadras a todos los restoranes del sector, etc. En general, el desarrollo de los centros urbanos ha observado este comportamiento dando lugar a barrios y zonas especializadas en ciertas actividades productivas y comerciales. Hotelling desarrolló un modelo en el cual dos empresas tratan de maximizar su participación en un mercado que posee una distribución uniforme de consumidores en un intervalo acotado. Estos consumidores pagan un costo de transporte proporcional a la distancia que recorren para llegar a la firma. Los resultados de la investigación sugirieron que, bajo ciertos supuestos, ambas firmas se localizarían en el centro del intervalo, posición que corresponde exactamente a la del consumidor mediano (aquel localizado justo a la mitad del intervalo). Él argumentaba que esta tendencia hacia el medio era algo aplicable en otros contextos y sugirió que la compe- 
tencia desarrollada por los actores políticos tiende a parecerse a la competencia geográfica entre actores económicos, y por esta razón los programas de gobierno ofrecidos por dos coaliciones que disputan el poder tienden a parecerse bastante en muchos aspectos. Lamentablemente Hotelling no desarrolló mayormente su idea, pero la dejó planteada para que treinta años más tarde otros investigadores la retomaran y desarrollaran lo que se conoce como teoría espacial del voto (TEV).

La TEV aparece como tal y arroja sus primeros resultados importantes con la publicación de la tesis doctoral de Downs (1957) y el libro seminal de Black (1958) donde se plantea el teorema del votante mediano. Este teorema argumenta que en una votación unidimensional ${ }^{18}$, si las preferencias de los votantes tienen un solo máximo, es decir, si dentro del universo de opciones existe una sola alternativa que satisface completamente sus preferencias, entonces, en una elección por mayoría simple, la alternativa que prefiere el votante mediano vence a cualquier otra alternativa que se presente, por lo tanto el votante mediano es quien decide el resultado de la votación. Este simple resultado es quizás uno de los más importantes en la TEV. Lamentablemente el teorema descansa en supuestos altamente restrictivos que han de ser relajados en los desarrollos subsecuentes.

Davis y Hinich (1966 y 1968) introdujeron la formulación matemática para preferencias multidimensionales de los votantes y Plott (1967) realizó una reformulación de los supuestos que se requieren para que el teorema del votante mediano tenga efecto en múltiples dimensiones, presentando las condiciones de simetría radial que garantizan la existencia de un ganador de Condorcet para el caso multidimensional ${ }^{19}$. Este resultado se fortaleció aún más cuando Davis, Hinich y Ordeshook (1970) demostraron que la existencia de un ganador de Condorcet, y por lo tanto la convergencia hacia una única plataforma político-electoral, predominaba aun cuando los votan-

${ }^{18}$ Una votación unidimensional es aquella que se centra en un único tema. Por ejemplo, el nivel de gasto en seguridad ciudadana como porcentaje del presupuesto fiscal del año.

${ }^{19}$ Para ejemplificar el ganador de Condorcet, suponga que existen tres votantes que están ubicados en el intervalo $(0,1)$. El votante A está en 0 , el votante B está en 0,5 y el votante $\mathrm{C}$ está en 1 . Si dos candidatos (I y D) se ubican políticamente en el mismo intervalo, entonces el candidato que se ubique en 0,5 es el ganador de Condorcet, dado que siempre obtendrá dos votos y, en consecuencia, la mayoría. Si el otro candidato se ubica entre 0 y 0,5 sólo obtendrá el voto de $A$, y si se ubica entre 0,5 y 1 sólo obtendrá el voto de C. Un ganador de Condorcet es simplemente una alternativa que no puede ser derrotada por ninguna otra en una elección por mayoría simple. Se le conoce así por Marie Jean Antoine Nicolas Cariat, marqués de Condorcet, quien a fines del siglo XVIII señaló algunos problemas en las formas de toma de decisión dentro de la Academia Francesa de Ciencias, criticó el análisis que Jean Charles de Borda introdujo años antes sobre el mismo tema y propuso nuevas soluciones al problema. 
tes estuvieran distribuidos en grupos con preferencias antagónicas y extremas. Más tarde Davis, Degroot y Hinich (1972) expandieron el resultado de Plott con la introducción del concepto de la mediana en todas las direcciones, llamado también el punto dominante, como el requisito para alcanzar el equilibrio en situaciones con múltiples dimensiones. Así, estos trabajos aportaron las condiciones necesarias para que exista una alternativa ganadora bajo una elección por mayoría cuando se trata de elegir un programa que incluye varios temas.

Un ejemplo práctico del teorema del votante mediano en su forma más simple es el clásico estudio de las votaciones en comité. Suponga que un comité formado por tres miembros tiene que decidir la cantidad de recursos a gastar en la compra de algún bien. Cada miembro del comité postula su mejor alternativa. Suponga que el miembro A quiere que se gaste 50, el miembro B quiere 100 y el miembro C quiere 200. Suponga además que para cada miembro del comité, alejarse en cualquier dirección de su alternativa óptima reduce su utilidad. Lo interesante es que el teorema del votante mediano predice con exactitud cuál será el resultado de esta votación, independiente del orden en la votación de las alternativas. Si se vota primero 50 contra 100, el miembro A elige 50 pero los miembros B y C eligen 100. Después se vota 100 contra 200, los miembros A y B eligen 100 y sólo el miembro $C$ elige 200. Por lo tanto la alternativa que siempre ganaría en este contexto es la alternativa del miembro $\mathrm{B}$, quien es justamente el votante mediano. La siguiente figura muestra la situación del comité y al votante mediano.

FIGURA N 1

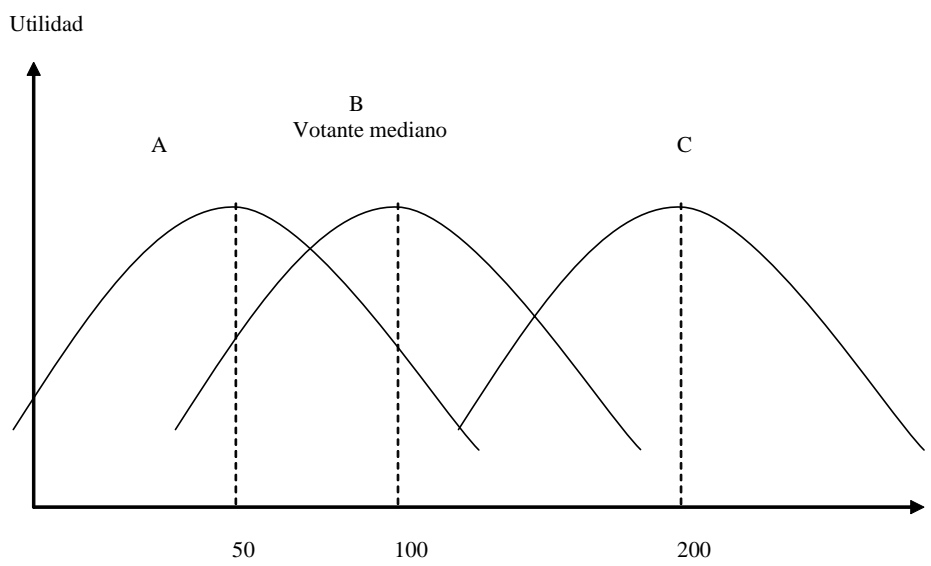


Uno de los dos problemas más relevantes en el desarrollo de la TEV es sin duda el señalado por Mckelvey (1976 y 1979) sobre el caos y la inestabilidad de los equilibrios en votaciones. Mckelvey observó que en el caso multidimensional la existencia de un ganador de Condorcet es excepcional, lo cual produce que el proceso de elección se repita infinitamente sin llegar nunca a un resultado estable, es decir que siempre existirá alguna alternativa viable que, en una segunda ronda de votos, pueda derrotar a cualquier resultado de una primera votación. Tullock (1981) argumenta que el caos y la inestabilidad encontrada en los modelos matemáticos formales de la literatura de la TEV no coinciden con la evidencia empírica y desafía a los estudiosos del tema a explicar esta aparente contradicción. Como respuesta se publicaron algunos intentos para explicar esta falta de coincidencia entre la teoría y la estabilidad observada en la realidad, sin embargo su éxito ha sido limitado. Una forma de tratar de dar respuesta a este problema es mediante explicaciones que aluden a factores institucionales. El argumento básico es que dado que la elección por mayoría simple lleva a problemas de inestabilidad y ya que los agentes políticos están conscientes de este problema, en la realidad las instituciones políticas han sido diseñadas de tal forma que la elección por mayoría simple sea la excepción y prevalezcan otras reglas de elección. Se ha argumentado que reglas institucionales como el bicameralismo y el poder de veto son instrumentos que proveen de estabilidad a los procesos de elección. Una de las líneas de investigación predominantes fue introducida por Romer y Rosenthal (1978) y Shepsle (1979) quienes desarrollaron el modelo del establecedor o diseñador de la agenda (o agenda setter), el cual responsabiliza del resultado de una votación y, en consecuencia, de la estabilidad alcanzada en los procesos de elección (especialmente en el contexto de votaciones de comité), a quien establece las reglas del juego o la agenda. Shepsle (1979) introdujo un concepto de carácter institucionalista respecto al equilibrio inducido por la estructura como una manera de explicar la estabilidad observada en el mundo real, y plantea que la limitación en el control de la agenda reduce los posibles resultados produciendo estabilidad en las votaciones. Más tarde, Shepsle y Weingast (1987) argumentaron que, en las votaciones de comité, el poder de control de la agenda es un factor determinante del grado de estabilidad del proceso.

Otro cuestionamiento importante a la TEV viene por el lado de la convergencia que la teoría predice respecto de las plataformas electorales que los partidos y candidatos en competencia debiesen tener. Hinich (1977), Coughlin (1984) y Ledyard (1984) demostraron que la esperada convergencia de las plataformas y programas electorales no es necesariamente la 
norma en la realidad, pues en muchos países existe una importante diferenciación de los partidos políticos e incluso hay grupos y partidos extremistas.

Los problemas de la disociación entre los resultados que los modelos formales (matemáticos) de la TEV predicen y la evidencia empírica observada en distintos países, ha dado un giro en los últimos años a la investigación de esta escuela, giro que su principal norte es la incorporación de aspectos de la realidad que acerque la teoría a la práctica.

En los últimos 20 años, los avances de la TEV han sido resultado de la incorporación de elementos más realistas que si bien es cierto aumentan la complejidad del modelo, al mismo tiempo lo hacen más cercano a lo que sucede en los hechos. Estos desarrollos pueden agruparse en dos líneas de análisis interrelacionadas. La primera es la que se centra en los problemas y características de los votantes. La segunda línea se enfoca en las características de los competidores.

Desarrollos por el lado de los votantes

En la primera línea de investigación se observaron los problemas de falta de información por parte de los electores sobre los candidatos. Así, al igual que en los modelos de ciclos políticos y de teoría de juegos, se incorporaron problemas de incertidumbre e información imperfecta con lo cual se rebasaron los modelos deterministas. Este refinamiento de la teoría se inicia con la incorporación del concepto de la votación probabilística que Enelow y Hinich (1982) introdujeron. En este tipo de estructuras, la incertidumbre que los votantes tienen acerca de los programas reales de los candidatos es modelada con una distribución de probabilidades que captura el hecho que todos los votantes tienen una probabilidad mayor que cero (por muy pequeña que sea) de votar por cada uno de los candidatos. La ubicación inicial de los votantes en el espectro político más el juego de señalización de los candidatos, es lo que hace a los votantes decidirse por uno u otro candidato.

Otro desarrollo reciente de la TEV es el del estudio de los mecanismos que los votantes utilizan para trasladar el discurso de los candidatos a posiciones de política pública, que es lo que finalmente interesa a los votantes. Aquí dos importantes aportes son los de Mckelvey y Ordeshook (1985), quienes introdujeron la idea del uso de las encuestas de opinión, y el aporte de Enelow y Hinich (1989) que introdujo el concepto de las dimensiones predictivas. 
Hinich y Munger (1994) atacan el problema del pobre refinamiento político del electorado usando el concepto de la ideología como mecanismo de simplificación en la información para la toma de decisiones. La TEV tradicionalmente asume que los votantes son capaces de ordenar preferencias sobre las posibles combinaciones de políticas en espacios multidimensionales. Esto implica un alto grado de información y refinamiento por parte de los electores, lo cual es bastante distinto de lo que se puede observar en la práctica. Hinich y Munger (1994) argumentan que en elecciones de masa los votantes usan la ideología como una manera de simplificar su evaluación sobre los candidatos. Se postula que la ideología ahorra tiempo y recursos, pues los votantes no necesitan conocer exactamente cuáles son las posiciones de política pública que los candidatos tienen sobre los temas relevantes para los votantes (salud, educación, regulación, temas morales, etc.). El conocer la ideología a la que los candidatos adhieren permite a los votantes inferir las posiciones de política pública de éstos sin mayor costo y así decidir su voto. Otros trabajos que desarrollan la idea de atajos (short cuts) son por ejemplo Lupia (1994), que estudia cómo los votantes poco informados sobre las propuestas de reforma al mercado de los seguros basan su decisión de voto en lo que hacen pequeños grupos mejor informados e interesados en una propuesta compleja. Otros trabajos en esta línea elaboran sobre la idea de que existe un atajo de género (gender short cut) que utilizan los votantes. Estas teorías sostienen que una candidata mujer es percibida como una persona ajena a la situación (outsider), alejada de los problemas de corrupción siempre existentes en la política (McDermott, 1998 y Valdini, 2005)

Modelos probabilísticos que se basan en expectativas también han sido introducidos en la literatura de la TEV. En estos modelos los electores construyen creencias sobre las características reales de los candidatos por lo que queda abierta la posibilidad de que estos últimos intenten señalizar sus características para tratar de ganar la elección. Esta idea es la que propone la teoría de movilización y que ha sido analizada por los estudios sobre el impacto de las campañas políticas en la opinión pública (Gerber y Jackson, 1990).

Desarrollos por el lado de los competidores

La otra línea de investigación relevante es la iniciada por las propuestas de Wittman $(1973,1983)$ sobre los incentivos de los competidores y el uso de modelos probabilísticos que difieren diametralmente de los supuestos que sustentan los modelos iniciales de la teoría espacial del voto 
donde los competidores no tienen preferencias sobre políticas sino sólo se interesan en obtener la máxima cantidad de votos para ganar las elecciones (véanse por ejemplo Kramer (1977), Hinich (1977)).

Wittman (1973) formaliza la idea de que los partidos políticos no sólo compiten para ganar la elección sino también para implementar las políticas concretas que les son de interés. Sin embargo, aún bajo el supuesto de que los competidores tienen preferencias sobre las políticas a realizar, Calvert (1985) demuestra que si la distribución de los electores sobre el espacio de políticas es conocido, los competidores tienden a converger hacia el votante mediano. Esto se debe a que si los competidores buscan implementar la política que ellos desean, primero deben ganar la elección y para ello deben convencer a los votantes y maximizar la obtención de votos. Para romper con el resultado del votante mediano, Wittman (1983) introdujo un modelo probabilístico que predice un comportamiento diferenciado de los candidatos mucho más acorde con los hechos reales. Alesina (1988) plantea que la convergencia de los partidos depende de su capacidad de compromiso para con sus plataformas electorales. Banks (1991) por su parte, tomando como base el problema de información asimétrica planteado por Wittman, presenta un modelo donde los candidatos pueden o no hacer públicas sus preferencias y demuestra que candidatos con posiciones moderadas tienden a la ambigüedad en sus plataformas mientras que los candidatos más extremistas tienden a revelar sus posiciones, así, la convergencia hacia el votante mediano prevalece y los candidatos extremistas se autoexcluyen de la competencia.

Los refinamientos posteriores a los trabajos de Downs y Wittman han ido en la dirección de modelar competidores heterogéneos. El reconocimiento de que los partidos, los gobiernos o los grupos de interés son entes compuestos por agentes con diferentes intereses ha llevado a desarrollar modelos del tipo de competidores colectivos y curvilíneos.

Alesina y Spear (1988) desarrollan el concepto de los competidores colectivos (los partidos políticos) en un modelo donde hay individuos que se encuentran ya en el gobierno y pueden ser reelectos durante un número de períodos determinado para luego retirarse. La manera de comportarse de los agentes es función de lo cerca que se está de retirarse. Un individuo que desea ser reelecto deberá comportarse más en función del votante mediano para asegurar su reelección, mientras que un individuo que está terminando su paso por el gobierno o que fue apenas electo en un sistema con no reelección o cuya reelección es lejana en el futuro, se comportará de acuerdo con sus propias preferencias. El resultado final dependerá también de 
otros factores como, por ejemplo, el nivel de disciplina o el grado de verticalidad del partido al que pertenecen.

Los modelos del tipo curvilíneo se basan en el argumento de Hirschman (1970), que sostiene que los individuos de posiciones extremas dentro de los partidos no buscan ganar la elección necesariamente sino más bien expresar sus posturas ideológicas. Así, en estos modelos los partidos están compuestos por agentes heterogéneos, en su versión más simple, aquellos que buscan ganar elecciones y los que quieren expresar posiciones ideológicas. Esto permite, al igual que con los modelos de generaciones traslapadas, que los partidos definan su posición tanto por la distribución de los votantes como por la distribución de los miembros que lo componen. Ya que los diferentes tipos de miembros que componen el partido tienen un papel relevante en la competencia electoral, los partidos como agentes unitarios deben presentar plataformas negociadas por estos agentes con lo cual son menos sensibles a la posición de los votantes, rompiéndose así el comportamiento de convergencia al votante mediano.

Los avances teóricos y las aplicaciones de estos modelos han sido muy amplios en los últimos años. Sin embargo, siendo tan reciente el desarrollo de estos modelos teóricos, sus resultados, aunque prometedores, aún son incipientes y sigue habiendo muchas discrepancias empíricas con respecto a las predicciones de estos modelos (Stokes, 1999). Trabajos como los de Iversen (1994a y 1994b), por ejemplo, evidencian una serie de contradicciones sobre las teorías de modelos curvilíneos en el caso del comportamiento de los partidos europeos.

Hasta aquí, los desarrollos que hemos mencionado consideran principalmente las características de los competidores políticos. Sin embargo es innegable que estos competidores responden a un contexto que determina los incentivos y las restricciones que enfrentan en el proceso de competencia. A partir de la década de los noventa, los análisis de carácter institucionalista recobraron importancia y han tenido un importante desarrollo dentro del estudio del comportamiento político en general y particularmente de la competencia política. Durante estos años este tipo de estudios han ido más allá del problema de control de la agenda en las votaciones de comité y han reincorporado los planteamientos de Durverger ([1951]1972) sobre el efecto de las reglas electorales en la competencia política. Cox (1987, 1990a y 1990b, 1991 y 1997) replanteó la importancia de las reglas electorales en el comportamiento partidista y ha utilizado argumentos de la TEV para determinar las condiciones en que los sistemas electorales inducen o no la convergencia de las plataformas políticas presentadas por diferentes com- 
petidores y de las políticas llevadas a cabo por los partidos en el poder. Dentro de los modelos formales de la TEV, el marco institucional se considera exógeno. Las instituciones (agencias y organizaciones que dan forma a la estructura del sistema electoral) en sí no se han modelado formalmente más allá del problema de la agenda. Sin embargo, el comportamiento racional de los agentes implica la acción estratégica para diseñar y transformar instituciones. Éste es uno de los temas más discutidos y menos logrados de la economía política neoclásica. Alesina y Rosenthal (1995), así como Boix (1999), han propuesto modelos formales que endogenizan las instituciones políticas, sin embargo sus desarrollos no se basan en la TEV. Ésta es pues una de las vetas que aún faltan por explorar en la TEV.

Otras líneas de desarrollo

En la mayoría de los desarrollos que se han dado en la TEV, el supuesto de una elección con dos candidatos es raramente relajado. Esto se debe fundamentalmente a dos razones. Primero, la influencia de las elecciones norteamericanas, donde dos grandes partidos son los que realmente se disputan el gobierno sin duda tiene su efecto en la literatura. Segundo, el pasar de un modelo simple a uno de múltiples candidatos agrega una complejidad de tratamiento matemático al análisis, sin que muchas veces haya una ganancia conceptual en el modelo. Sin embargo, existen intentos de introducir modelos de múltiples candidatos en la literatura. Los trabajos de Cox $(1987,1990 b)$ estudian elecciones con candidatos múltiples bajo diferentes reglas de elección. Cox observa que, en votaciones múltiples y determinísticas, es raro encontrar equilibrios, otro resultado desalentador desde un punto de vista teórico.

Otro supuesto raramente relajado en la TEV es el del conocimiento común. Prácticamente todas las teorías formales que aquí hemos mencionado suponen que los agentes comparten las mismas distribuciones de probabilidad condicional cuando existe información asimétrica o incertidumbre sobre las características o el comportamiento de uno o varios agentes. Esto implica que todos los agentes tienen el mismo acceso a los datos que les permiten construir sus expectativas. Sin embargo, en la realidad este tipo de recursos no son bienes públicos ni se distribuyen de forma homogénea entre los diferentes agentes políticos. La adquisición de estos recursos y la formación de expectativas a partir de ellos no se han logrado endogenizar en función de las características particulares de los diferentes agentes. 
Las diferencias en la distribución de poder han sido analizadas en modelos de negociación ${ }^{20}$, sin embargo son aún pocos los modelos espaciales que consideran la dinámica que estas diferencias entre los agentes imprimen en los procesos de elección. La capacidad de manipular información es uno de estos aspectos que apenas comienza a ser explorado en modelos basados en la TEV ${ }^{21}$.

El terreno natural de la TEV ha sido el de la competencia electoral. No obstante, la teoría espacial tiene un potencial de aplicación más allá de los procesos electorales. La búsqueda de apoyo político ya sea por la vía del desempeño gubernamental, de mecanismos de cliente-patrón o a través de prácticas coercitivas, ha comenzado a ser considerada muy recientemente en algunos modelos que explican procesos políticos más allá de los electorales. El potencial dentro de esta línea de análisis es de gran importancia y apenas inicia su desarrollo ${ }^{22}$.

Finalmente, otro tópico a desarrollar en el futuro es la incorporación formal del concepto de ideología en la $\mathrm{TEV}^{23}$. La ideología es una idea antigua en el estudio de la filosofía y las ciencias políticas, sin embargo, su incorporación formal en modelos matemáticos basados en el paradigma de la elección racional y la competencia política es algo innovador que seguramente será explotada en los años venideros.

Un ejemplo del uso del concepto de ideología es el siguiente. Supongamos que para los votantes uno de los temas importantes para la próxima elección es la posición de los candidatos en la política pública relacionada con el gasto en defensa y el gasto en salud pública. Para los electores es costoso informarse en detalle de todas las propuestas de los candidatos (habría que leer los programas de los candidatos), y por eso esta teoría postula que los votantes utilizan el mecanismo simplificador de la ideología para mapear, desde el espacio de la ideología hasta el espacio de las políticas públicas, la posición que los candidatos tendrían en materia de gasto en defensa y salud. La siguiente figura muestra el mapeo que los votantes realizan a la hora de inferir las posiciones de los candidatos.

El ejemplo contiene dos parámetros, el intercepto $b$ y la pendiente $v$. El intercepto representa la percepción que los electores tienen del statu

${ }^{20}$ Véanse por ejemplo Knigth (1992) y Doron y Sened (2001).

21 Véase por ejemplo Bonilla (2004), quien ha propuesto un modelo sobre inversión en campañas políticas y el uso de recursos en la manipulación de información.

${ }^{22}$ Dos de los trabajos más recientes son LaFerrara y Bates (2001) y Gatica (2005).

${ }^{23}$ Incipientes intentos por modelar ideología se han hecho (véase Hinich y Munger, 1994, o Bonilla, 2004) 
FIGURA N 2

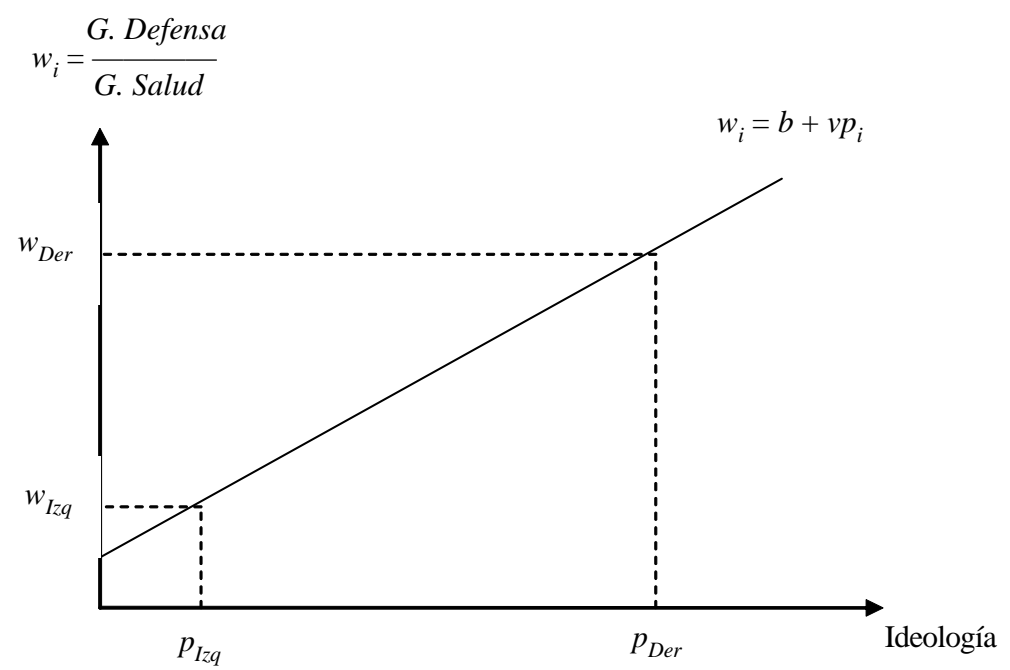

quo. La pendiente representa la relación (lineal en este ejemplo) entre ideología y política pública. Finalmente, $p_{i}$ representa la ideología a la que pertenece el candidato $i$, según la percepción de los electores.

Sin embargo, aún falta mucho por entender del comportamiento de las organizaciones políticas y su composición interna. Pero el principal desafío que se avecina es el de unir en un solo modelo los diversos avances que la TEV está experimentando en líneas de investigación paralelas, para así llegar a construir modelos más completos que resulten en un cuerpo coherente y más realista. Sólo así se podrá seguir acercando la teoría altamente sofisticada a la experiencia del actuar de los gobiernos. Hasta ahora, esta unificación sigue siendo de una alta complejidad formal, lo cual ha limitado en cierta medida el avance de la teoría. Afortunadamente el desarrollo de la tecnología, el acceso a cada vez mejores y más sofisticados sistemas de cómputo y el consecuente desarrollo de métodos de estimación, simulación y análisis numérico, está permitiendo la construcción y el estudio de modelos más completos y realistas ${ }^{24}$. Ésta es, pues, un área de gran

${ }^{24}$ Algunas revisiones generales sobre el uso de métodos computacionales en ciencia política y economía son Johnson (1999), Judd (2001), Tesfatsion (2001) y Vriend (2002). Una compilación sobre trabajos recientes en modelos computacionales en economía política es el libro editado por Kollman, Miller y Page (2003). Para el caso de la TEV, véanse por ejemplo Bailey (2003), De Marchi (2003) y Jakson (2003). 
importancia en la construcción de mejores teorías, cada vez más coherentes con el comportamiento real de los actores políticos.

La teoría espacial del voto (TEV) y el enfoque racional en las ciencias políticas no ha estado ausente de críticas. En su famoso libro Pathologies of Rational Choice Theory: A Critique of Applications in Political Science (1994), Green y Shapiro sostienen que el gran problema que presentan los modelos basados en el enfoque racional es la ausencia de resultados empíricos que sustenten los modelos teóricos matemáticos. Ellos argumentan que estos modelos están basados en un sinnúmero de conjeturas imposibles de testear en la práctica. Otros autores como Ordeshook (1996) han sostenido que los modelos de elección racional en ciencias políticas deben ser vistos como una ciencia, donde la ingeniería debe todavía ser trabajada. Sin duda, esta controversia seguirá en los años venideros, y en la medida que la teoría y la práctica converjan, amantes y críticos de la teoría espacial y otros modelos formales encontrarán puntos comunes.

\section{Conclusiones}

Dentro de la economía política neoclásica el desarrollo formal más importante es sin duda la TEV. Si bien éste se inició hace ya medio siglo, en la actualidad sigue siendo una de las áreas más relevantes y prometedoras de investigación. Sus principios más básicos y simples son un gran instrumento para comprender un importante número de fenómenos políticos. Estos principios planteados inicialmente por Hotteling y desarrollados posteriormente por Black y Downs, son la base de las formalizaciones más eficientes sobre el actuar de los agentes políticos durante procesos de competencia, particularmente durante períodos electorales.

El incentivo que tienen los gobiernos por mantenerse en el poder y el de sus competidores por acceder a él, le ha dado a esta teoría una predominancia en el análisis del actuar del gobierno y en la explicación de la implementación de muchas políticas públicas.

Aun cuando la TEV tiene un fundamento de carácter microeconómico, esto no ha sido limitante alguna para que sus principales resultados se apliquen constantemente a los análisis macroeconómicos que consideran el aspecto político de los fenómenos sociales.

En los últimos años, esta teoría ha avanzado hacia explicaciones más sofisticadas de los procesos de competencia política, inicialmente señalando los problemas de correspondencia con la realidad que ha presentado 
como producto de su construcción formal. La solución de estos problemas ha evolucionado hacia la construcción de modelos que incorporan elementos tales como diferencias en recursos, poder, información, instituciones y factores sociales de credibilidad y confianza. La introducción de estos factores, no sólo ha permitido resolver algunos de los problemas de correspondencia, sino que les ha proporcionado más realismo y por lo tanto les ha impreso mayor capacidad predictiva y de aplicación empírica. Esta sofisticación ha llevado a la aplicación de la TEV más allá de los procesos puramente electorales y ha generado la búsqueda de nuevos métodos de formalización y de análisis, en particular el uso de métodos computacionales.

Como toda teoría relativamente joven, la TEV adolece de problemas que aún requieren de soluciones. Sin embargo, la relevancia que esta teoría tiene en el análisis político-económico le da un amplio margen para su futuro desarrollo. La relativa dispersión de los modelos teóricos deja abierta la posibilidad de una mayor y mejor integración de éstos, por supuesto sin que ello implique la pretensión de construir modelos totalizadores.

\section{APÉNDICE}

\section{Un modelo simple de la teoría espacial del voto}

Sea $K$ el conjunto de los candidatos a elegir, $I$ el conjunto de votantes y $J$ el conjunto de empresas que financian a los candidatos.

$$
U_{i}\left(\pi_{k}\right)=-\left(\pi_{k}-x_{i}\right)^{2}
$$

es la utilidad que el votante $i$ alcanza si el candidato $k$ es elegido. Donde $x_{i}$ es el "punto ideal" o de máxima felicidad para el votante $i$, y $\pi_{k}$ es la posición del candidato $k$. Claramente el votante $i$ votará por el candidato que tenga mayor cercanía con él pues es el que genera la mayor utilidad.

Por otra parte, las empresas "invertirán” en el candidato $k$ hasta que el beneficio marginal ${ }^{25}$ esperado del candidato $k$ sea igual al costo marginal de seguir invirtiendo en él

$$
p_{k} B m g_{j, k}=r_{j}
$$

${ }^{25}$ En la literatura de la TEV, los beneficios que los candidatos generan para las empresas son conceptualizados como favores que éstos devuelven a las empresas y que tienen directa incidencia en las utilidades de las empresas. 
donde $p_{k}$ es la probabilidad de que el candidato $k$ sea elegido $\mathrm{y} r_{j}$ es el retorno del mejor proyecto alternativo para la empresa $j$. La ecuación anterior implícitamente define el aporte que la empresa $j$ hará al candidato $k$, es $\operatorname{decir} C_{j, k}$.

Los candidatos necesitan recursos de las empresas por dos motivos. Primero, para señalizar su propia posición $\pi_{k}$ a los electores, y segundo, para introducir ruido a las señales de sus adversarios $\pi_{q}$.

Sea $s_{k}$ lo que el candidato $k$ gasta en señalizar su posición, y sea $o_{k}^{q}$ la cantidad que el candidato $k$ gasta en introducir ruido a la señal de sus adversarios q. Entonces, la restricción presupuestaria que enfrentan los candidatos es

$$
\sum_{j \in J} C_{j, k} \geq S_{k}+\sum_{(q \neq k) \in K} o_{k}^{q} .
$$

Definamos el diferencial neto de la utilidad esperada para el votante $i$ del candidato $k\left(D N U E_{i, k}\right)$ como

$$
E\left\{U_{i}\left(\pi_{k}\left(s_{k}, \sum_{q \in K} o_{q}^{k}\right)\right)\right\}-\sum_{q \in K} E\left\{U_{i}\left(\pi_{q}\left(s_{q}, \sum_{j \in K} o_{j}^{q}\right)\right)\right\}
$$

Podemos ver que a mayor $D N U E_{i, k}$ aumenta la probabilidad de que el votante $i$ vote por en candidato $k$.

Sea $F(\cdot)$ la función de densidad acumulada de la probabilidad que el votante $i$ vote por el candidato $k$ dado el $D N U E_{i, k}$. Entonces, en equilibrio de competencia política espacial tenemos que cada candidato $k$ maximiza $\sum_{i \in I} F\left(D N U E_{i, k}\right)$ sujeto a su restricción presupuestaria. El equilibrio genera un vector con los $s^{*}$ y $o^{*}$ óptimos para todos y cada uno de los candidatos en competencia.

\section{REFERENCIAS}

Ainsworth, Scott y Sened (1993): “Regulating Lobbyists and Interest Group Influence”. En The Journal of Politics, 55: 41-56.

Akerlof, George A. (1970): “The Market for 'Lemons': Quality Uncertainty and the Market Mechanism”. En The Quarterly Journal of Economics, Vol. 84 (3): 488-500, MIT Press.

Alesina, Alberto (1988): “Credibility and Policy Convergence in a Two-party System with Rational Voters”. En American Economic Review, 78: 796-806.

Aldrich, John H. (1993): "Rational Choice and Turnout". En American Journal of Political Science, 37: 246-278.

Alesina, Alberto y Stephen Spear (1988): “An Overlapping Generation Model of Electoral Competition”. En Journal of Public Economics, 37: 359-79. 
Alesina, Alberto y D. Rodrik (1994): “Distributive Politics and Economic Growth”. En Quarterly Journal of Economics, 112: 1027-1056.

Amadae, S. M. y B. Bueno de Mesquita (1999): "The Rochester School: The Origins of Positive Political Economy”. En Annual Review of Political Science, 2: 272278.

Arrow, Ken (1951): Social Choice and Individual Values. New Heaven: Yale University Press.

Austen-Smith, David y William Riker (1987): “Asymmetric Information and the Coherence of Legislation”. En American Political Science Review, 81: 897-918.

Austen-Smith, David y Jeffrey Banks (1989): "Electoral Accountability and Incumbency”. En Peter Ordeshook (ed.), Models of Strategic Choice in Politics. Ann Arbor: University of Michigan Press.

Austen-Smith, David y Jeffrey Banks (1990): "Stable Governments and the Allocation of Policy Portafolios”. En American Political Science Review, 84: 891-906.

Austen-Smith, David y William Riker (1990): “Asymmetric Information and the Coherence of Legislation: A Correction”. En American Political Science Review, 84: 243-245.

Austen-Smith, David (1990): "Information Transmission in Debate". En American Journal of Political Science, 34: 124-152.

Austen-Smith, David (1993): "Information and Influence: Lobbying for Agendas and Votes”. En American Journal of Political Science, 37: 799-833.

Bailey, Michael (2003): "The Other Side of the Coin: A Computational Analysis of Publicly Financed Campaigns”. En Ken Kollman, John H. Miller y Scott E. Page (ed.), Computational Models in Political Economy. Cambridge, MA: MIT Press: 159-186.

Banks, Jeffrey (1991): Signalling Games in Political Science. Chur, Suiza: Harwood Academic Publishers.

Bardhan, Pranab (1989): “Alternative Approaches to the Theory of Institutions in Economic Development”. En P. Bardhan (ed.), The Economic Theory of Agrarian Institutions. Oxford: Clarendon Press.

Bardhan, Pranab y Chistopher Urdy (1999): Development Microeconomics. Oxford: Oxford University Press.

Baron, David (1993): “Government Formation and Endogenous Parties”. En American Political Science Review, 87: 34-47.

Bates, Robert (1981): Markets and States in Tropical Africa: The Political Basis of Agrarian Policies. Berkeley y Los Angeles: University of California Press.

Bates, Robert (1989): Beyond the Miracle of the Market: The Political Economy of Agrarian Development in Rural Kenya. New York: Praeger.

Bates, Robert (1990): "Capital, Kingship and Conflict: The Structuring Influence of Capital in Kingship Societies”. En Canadian Journal of African Studies, 2: 151-164.

Bates, Robert, A. Greif, M. Levi, J-L. Rosenthal y B. Weingast (1998): Analytic Narratives. Princeton: Princeton University Press.

Bates, Robert, A. Greif, M. Levi, J-L. Rosenthal y B. Weingast (2000): “The Analytical Narrative Project”. En American Political Science Review, 94, 3: 696-702.

Becker, Gary (1983): “A Theory of Competition Among Pressure Groups for Political Influence”. En Economic Journal, 108: 1795-1809. 
Becker, Gary (1985): “Public Policies, Pressure Groups and Deadweight Costs”. En Quarterly Journal of Economics, 98: 371-400.

Benoit, Kenneth (2004): "Models of Electoral System Change”. En Electoral Studies, 23, 3: 363-389.

Binswagner, Hans y Vernon W. Ruttan (eds) (1978): Induced Innovations: Technology, Institutions, and Development. Baltimore: Johns Hopkins University Press.

Binswagner, H. P. y M. R. Rosenzweig (1984): "Behavioural and Material Determinants of Production Relations in Agriculture”. World Bank, Research Unit, Agriculture and Rural Development Department, Report No. ARU5.

Black, Duncan (1958): The Theory of Committees and Elections. Cambridge, England. Cambridge University Press.

Boix, Carles (1999): “Setting the Rules of the Game: The Choice of Electoral Systems in Advanced Democracies”. En American Political Science Review, 92, 2: 329342.

Bonilla, Claudio (2004): “A Model of Political Competition in the Underlying Space of Ideology”. En Public Choice, 121, 51-67.

Buchanan, James M. y Gordon Tullock (1962): The Calculus of Consent. Ann Arbor: University of Michigan Press. [Existen traducciones al castellano en PlanetaDe Agostini y Espasa-Calpe.]

Bueno de Mesquita, Bruce y David Lalman (1992): War and Reason: Domestic and International Imperatives. New Heaven: Yale University Press.

Calvert, R. (1985): “Robustness of the Multidimensional Voting Model: Candidates' Motivations, Uncertainty, and Convergence”. En American Journal of Political Science, 29: 69-95.

Carey, John y Mathew Soberg Shugart (1995): “Incentives to Cultivate a Personal Vote: A Rank Ordering of Electoral Formulas”. En Electoral Studies, 14, 4: 417-439.

Chang, R. (1990): “International Coordination of Fiscal Deficits”. En Journal of Monetary Economics, 25: 3.

Chhibber, Pradeep y Kenneth Kollman (1998): "Party Aggregation and the Number of Parties in India and the United States”. En American Political Science Review, 93, 3: 329-342.

Coase, R. H. (1937): “The Nature of the Firm”. En Economica, 4, 16: 386-405.

Coase, R. H. (1960): “The Problem of Social Cost”. En Journal of Law and Economics 3, 1: 1-44. [Traducción al castellano en Estudios Públicos, 45 (1992).]

Cohen, A. (1981): Custom and Politics in Urban Africa. Berkeley y Los Angeles: University of California Press.

Coughlin, Peter J. (1984): “Expectations about Voter Choices: a Comment”. En Public Choice, 44: 49-59.

Coughlin, Peter J. (1990): “Majority Rule and Election Models”. En Journal of Economic Surveys, 3: 157-188.

Cox, Gary (1987): “Electoral Equilibrium Under Alternatives Voting Institutions”. En American Journal of Political Science, 31: 82-108.

Cox, Gary (1990a): “Centripetal and Centrifugal Incentives in Electoral Systems”. En American Journal of Political Science, 34: 903-935.

Cox, Gary (1990b): “Multicandidate Spatial Competition”. En James Enelow y Melvin Hinich, eds., Advances in the Spatial Theory of Voting. Cambridge: Cambridge University Press. 
Cox, Gary (1991): “STNV and d'Hondt Are 'Equivalent'”. En Electoral Studies, 10, 118-132.

Cox, Gary (1997): Making Votes Count: Strategic Coordination in the World's Electoral System. New York: Cambridge University Press.

Davis, Lance y Douglas North (1971): Institutional Change and American Economic Growth. Cambridge: Cambridge University Press.

Davis, Otto y Melvin J. Hinich (1966): “A Mathematical Model of Policy Formation in Democratic Societies”. En Joseph Benvd (ed.), Mathematical Applications in Political Science, II. Dallas: Southern Methodist University Press.

Davis, Otto, Hinich y Ordeshook (1970): “An Expository Development of a Mathematical Model of the Electoral Process”. American Political Science Review, 54:426-448.

Davis, Otto, Morris Degroot y Melvin J. Hinich (1972): “Social Preference Ordering and Majority Rule”. En Econometrica, 40: 147-157.

De Marchi, Scott (2003): “A Computational Model of Voter Sophistication, Ideology, and Candidate Position Taking”. En Ken Kollman, John H. Miller y Scott E. Page (ed.), Computational Models in Political Economy. Cambridge, MA: MIT Press: 143-158.

Dixit, A. (1996): "Special Interest Politics and Endogenous Commodity Taxation”. En Eastern Economic Journal, 22: 375-388.

Dixit, A. (1997): “Power of Incentives in Private vs. Public Organizations”. En American Economic Review, 87: 378-382.

Dixit, A., G. Grossman y E. Helpman (1997): “Common Agency and Coordination: General Theory and Application to Government Policy Making”. En Journal of Political Economy, 105: 752-769.

Dixit, A. (1999): “A Repeated Game Model of Monetary Union”. Mimeo, Princeton University, Princeton.

Doron, Gideon y Itai Sened (2001): Political Bargaining: Theory, Practice and Process. California: SAGE Publications Inc.

Downs, Anthony (1957): An Economic Theory of Democracy. New York: Harper and Row.

Duverger, Maurice [1951] (1972): Los Partidos Políticos. México D.F.: Fondo de Cultura Económica.

Elster, Jon (2000): "Rational Choice History: A Case of Excessive Ambition”. En American Political Science Review, 94, 3, 685-695.

Enelow, James y Melvin J. Hinich (1982): “Ideology, Issues, and the Spatial Theory of Elections”. En American Political Science Review, 76: 493-501.

Enelow, James y Melvin J. Hinich (1984): The Spatial Theory of Voting: An Introduction. New York: Cambridge University Press.

Enelow, James y M. Hinich (1989): “A General Probabilistic Spatial Theory of Elections. Public Choice, 61: 101-113.

Enelow, James y Melvin J. Hinich (1990): “The Theory of Predictive Mappings”. En James Enelow y Melvin Hinich (eds.). Advances of the Spatial Theory of Voting. New York. Cambridge University Press.

Fearon, James D. (1994): “Signaling versus the Balance of Power and Interests”. En Journal of Conflict Resolution, 38: 236-269.

Feeny, David (1982): The Political Economy of Productivity: Thai Agricultural Development 1880-1975. Vancouver: University of British Columbia Press. 
Feeny, David (1988): “The Development of Property Rights in Land”. En Robert H. Bates (ed.), Toward a Political Economy of Development. Berkeley y Los Angeles: California University Press.

Ferejohn, J. y Morris Fiorina (1975): "Purposive Models of Legislative Behavior”. En American Economic Review, Papers and Proceedings, 65: 407-415.

Ferejohn, John (1986): "Incumbent Performance and Electoral Control". En Public Choice, 50: 5-25.

Fisher, Stanley (1988): “International Macroeconomic Policy Coordination”. En M. Feldstein (ed.), International Economic Coordination. Chicago: University of Chicago Press.

Friedman, Jeffrey (1996): The Rational Choice Controversy: Economic Models of Politics Reconsidered. New Heaven: Yale University Press.

Gatica, Leonardo A. (2005): "Government Performance and Competition for Political Support in Divided Political Organizations: A Formal Model”. Artículo presentado en el congreso anual de la American Political Science Association, Chicago.

Gerber, E. R. y J. E. Jackson (1990): "Endogenous Preferences and the Study of Institutions”. Artículo presentado en el congreso anual de la American Political Science Association, San Francisco.

Gilligan, Thomas W. y Keith Krehbiel (1987): “Collective Decision-Making and Standing Committees: An Informational Rationale for Restrictive Amendment Procedures”. En Journal of Law, Economics and Organization, 3: 287-335.

Gilligan, Thomas W. y Keith Krehbiel (1989): “Asymmetric Information and Legislative Rules with a Heterogeneous Committee”. En American Journal of Political Science, 33: 459-490.

Gilligan, Thomas W. y Keith Krehbiel (1990): “Organization of Informative Committees by a Rational Legislature”. En American Journal of Political Science, 34: 531-564.

Gilpin, Robert (1981): War and Change in International Politics. Cambridge: Cambridge University Press.

Green, Donald y Ian Shapiro (1994): Pathologies of Rational Choice Theory: A Critique of Applications in Political Science. New Haven: Yale University Press.

Greenberg J. y Shepsle K. (1987): "The Effect of Electoral Rewards in Multiparty Competition with Entry”. En The American Political Science Review, Vol. 81, $\mathrm{N}^{\circ} .2$ (June 1987): 525-538.

Grossman, Gene y Elhanan Helpman (1995): “The Politics of Free Trade”. En American Economic Review, 85: 667-690.

Grossman, Gene y Elhanan Helpman (1996): “The Politics of Free-trade Agreements”. En Review of Economic Studies, 63: 265-286.

Grossman, Gene y Elhanan Helpman (2002a): Special Interest Politics. Cambridge: MIT Press.

Grossman, Gene y Elhanan Helpman (2002b): Special Interest Groups and Trade Policy. Princeton: Princeton University Press.

Guttman, Joel M. (1978): “Interest Groups and Demand of Agricultural Research”. En Journal of Political Economy, 86: 467-484.

Guttman, Joel M. (1980): "Villages as Interest Groups: The Demand for Agricultural Extension Services in India”. En Kyklos, 33: 122-141. 
Hall, Peter A. y Rosemary C. R. Taylor (1996): "Political Science and the Three New Institutionalisms”. En Political Studies, XLIV: 936-957.

Hayami, Yujiro y Vernon W. Ruttan (1971): Agricultural Development: An International Perspective. Baltimore: Johns Hopkins University Press.

Hinich, Melvin J. (1977): “Equilibrium in Spatial Voting: the Medium Voter Result is an Artifact”. En Journal of Economic Theory, 16: 208-219.

Hinich, Melvin J. y Michael Munger (1994): Ideology and the Theory of Political Choice. Ann Arbor. University of Michigan Press.

Hinich, Melvin J. y Michael Munger (1997): Analytical Politics. Cambridge: Cambridge University Press.

Hirschman, A. O. (1970): Exit, Voice and Loyalty. Cambridge, MA: Harvard University Press.

Hotelling, Harold (1929): “Stability in Competition”. En Economic Journal, 39: 4157.

Huber, John D. (1992): "Restrictive Legislative Procedures in France and the United States”. En American Political Science Review, 86: 1155-1174.

Hug, Simon (2001): Altering Party Systems: Strategic Behavior and the Emergence of New Political Parties in Western Europe. Ann Arbor: University of Michigan Press.

Iida, Keisuke (1993): "When and How Do Domestic Constraints Matter? Two Level Games with Uncertainty”. En Journal of Conflict and Resolution, 37: 403-426.

Iversen, T. (1994a): "The Logics of Electoral Politics: Spatial, Directional and Mobilizational Effects”. En Comparative Political Studies, 27(2): 155-189.

Iversen, T. (1994b): "Political Leadership and Representation in Western European Democracies: A Test of Three Models of Voting”. En American Journal of Political Science, 38: 45-74.

Jackson, John E. (2003): “A Computational Theory of Electoral Competition”. En Ken Kollman, John H. Miller y Scott E. Page (eds.), Computational Models in Political Economy. Cambridge, MA: MIT Press: 109-142.

Jevons, William Stanley [1871] (1957): The Theory of Political Economy. New York: Kelley and Millman.

Johnson, Paul (1999): "Simulation Modeling in Political Science”. En American Behavioral Scientist, 42: 1509-30.

Judd, Kenneth (2001): “Computation and Economic Theory”. En Economic Theory, 18: $1-6$.

Kalyvas, Stathis (1996): The Rise of Christian Democracy in Europe. Ithaca, NY: Cornell University Press.

Kennedy, Paul M. (1987): The Rise and Fall of the Great Powers: Economic Change and Military Conflict from 1500 to 2000. New York: Random House.

Khan, M. H. (1995): "State Failure in Weak States: A Critique of New Institutionalist Explanations”. En John Harriss, Janet Hunter y Colin M. Lewis (eds.), The New Institutional Economics and Third World Development. London: Routledge.

Kilgour, Marc y Frank C. Zagare (1991): “Credibility, Uncertainty, and Deterrence”. En American Journal of Political Science, 35, 2: 85-103.

Kitschelt, Herbert (1989): The Logics of Party Formation: Ecological Politics in Belgium and West Germany. Ithaca: Cornell University Press.

Kitschelt, Herbert (1994): The Transformation of European Social Democracy. New York: Cambridge University Press. 
Knight, Jack (1992): Institutions and Social Conflict. Cambridge: Cambridge University Press.

Kollman, Ken, John H. Miller y Scott E. Page (2003): Computational Models in Political Economy. Cambridge, MA: MIT Press.

Kostadinova, Tatiana (2002): "Do Mixed Electoral Systems Matter?: A Crossnational Analysis of their Effects in Eastern Europe”. En Electoral Studies, 21: 23-34.

Kramer, G. (1977): “A Dynamical Model of Political Equilibrium”. En Journal of Economic Ttheory, 16, 310-334.

Krehbiel, Keith (1991): Information and Legislative Organization. Ann Arbor: University of Michigan Press.

Krusell, Per, Vincenzo Quadrini y José Víctor Ríos Rull (1997): “Political-Economic Equilibrium and Economic Growth”. Journal of Economic Dynamics and Control, 21, 1: 243-272.

Krusell, P. y V. Rios Rull (1999): “On the Size of the U.S. Government: Political Economy in the Neoclasical Growth Model”. En American Economic Review, 98, 5: 1156-1181.

La Ferrara, Eliana y Robert Bates (2001): "Political Competition in Weak States”. En Economics and Politics, Vol. 3, No 2.

Laitin, David (1993): “The Game Theory of Language Regimes”. En International Political Science Review, 14.

Laitin, David (1998): Identity in Formation: The Russian-Speaking Populations in the Near Abroad. Ithaca: Cornell University Press.

Laitin, David (1999): “National Revivals and Violence”. En John Bowen y Roger Petersen (eds.), Critical Comparisons in Politics and Culture. New York: Cambridge University Press.

Laver y Shepsle (1990): “Coalitions and Cabinet Government”. En American Political Science Review, 84: 873-90.

Laver y Schofield (1990): Multiparty Government: The Politics of Coalitions in Europe. New York: Oxford University Press.

Ledyard, John O. (1984): "The Pure Theory of Large Two-Candidate Elections". En Public Choice, 48: 7-41.

Levi, Margaret (1997): “A Model, a Method and a Map: Rational Choice in Comparative and Historical Analysis”. En Mark Lichbach y Alan Zuckerman (eds.), Comparative Politics: Rationality, Culture and Structure. New York: Cambridge University Press.

Leys, Colin (1996): The Rise and Fall of Development Theory. Londres: EAEP. Indiana University Press-James Currey.

Lichbach, Mark (2002): Is Rational Choice All of Social Science? Ann Arbor: University of Michigan Press.

Lijphart, Ardend (1994): Electoral Systems and Party Systems: A Study of TwentySeven Democracies, 1945-1990. Oxford: Oxford University Press.

Lupia, Arthur (1994): "Shortcuts Versus Encyclopedias: Information and Voting Behavior in California Insurance Reformations”. En American Political Science Review, 88, 1: 63-75.

Mair, Peter (ed.) (1990): The West European Party System. Oxford: Oxford University Press. 
McDermott, Monika (1998): “Race and Gender in Low Information-Elections”. En Political Research Quarterly, 51, 4: 895-918.

McKelvey, Richard (1976): "Intransitivities in Multidimensional Voting Models and Some Implications for Agenda Control”. En Journal of Economic Theory, 12: 472-82.

Mckelvey, Richard (1979): “General Conditions for Global Intransitivities in Formal Voting Models”. Econometrica, 47: 1085-1111.

Mckelvey, Richard y Peter Ordeshook (1985): "Election with Limited Information: A Fulfilled Expectation Model Using Contemporaneous Poll and Endorsement Data as Information Sources”. En Journal of Economic Theory, 36: 55-85.

Meltzer, A. y S. Richard (1981): “A Rational Theory of the Size of Government”. En Journal of Political Economy, 89: 914-927.

Miller, Gary (1997): “The Impact of Economics on Contemporary Political Science”. En Journal of Economic Literature, 35 (3): 1173-1204.

Moe, Terry (1984): “The New Economics of Organization”. En American Journal of Political Science, 28: 739-177.

Montiel, P. (1993): Informal Financial Markets in Developing Countries. Oxford: Blackwell.

Morrow, James D. (1996): Game Theory for Political Scientists. New Jersey: Princeton University Press.

Moser, Robert (2002): Unexpected Outcomes: Electoral Systems, Political Parties and Representation in Russia. Pittsburgh: University of Pittsburgh Press.

Munck, Gerardo (2001): “Game Theory and Comparative Politics: New Perspectives and Old Concerns”. En World Politics, 53, 173-204.

Niou, E. y P. Ordeshook (1989): "Stability in International Systems and The Costs of War”. En P. C. Ordeshook (editor), Models of Strategic Choices in Politics. University of Michigan Press.

Niou, E. y P. Ordeshook (1990): “Stability in Anarchic International Systems”. En American Political Science Review, 84 (4) December 1990: 1205-1234.

Nordhaus, William (1975): “The Political Business Cycle”. En Review of Economic Studies, April 1975: 169-190.

North, Douglas C. y Robert Paul Thomas (1973): The Rise of the Western World: A New Economic History. Cambridge: Cambridge University Press.

North, Douglas C. (1981): Structure and Change in Economic History. New York: W. W. Norton \& Company. [Existe traducción al castellano en Editorial Alianza.]

North, Douglas C. y Barry R. Weingast (1989): “Constitutions and Commitment: The Evolution of Institutions Governing Public Choice in Seventeen Century England”. En Journal of Economic History, 49 (4): 803-832.

North, Douglas C. (1990): Institutions, Institutional Change and Economic Performance. Cambridge: Cambridge University Press. [Existe traducción al castellano en el Fondo de Cultura Económica.]

O’Neill, Barry (1992): “A Survey of Game Theory Models of Peace and War”. En Robert Aumann y Sergiu Hart (eds.), Handbook of Game Theory, Vol. 2. New York: Springer-Verlag.

Olson, Mancur (1971): The Logic of Collective Action. Cambridge, MA: Harvard University Press.

Olson, Mancur (1982): The Rise and Decline of Nations: Economic Growth, Inflation and Social Rigidities. New Heaven: Yale University Press. 
Olson, Mancur (2000): Power and Prosperity: Outgrowing Communist and Capitalist Dictatorships. Basic Books.

Ordeshook, Peter C. (1997): "The Spatial Analysis of Elections and Committees: Four Decades of Research”. En Dennis C. Muller (ed.), Perspectives on Public Choice. Cambridge: Cambridge University Press.

Ostrom, Elinor (1990): Governing the Commons: The Evolution of Institutions for Collective Action. New York: Cambridge University Press.

Ostrom, Elinor (1998): “A Behavioural Approach to the Rational Choice Theory of Collective Action: Presidential Address, American Political Science Association, 1997”. En American Political Science Review, 92, 1, pp. 1-22.

Palfrey, Thomas R. y Howard Rosenthal (1985): "Voter Participation and Strategic Uncertainty”. En American Political Science Review, 79: 62-78.

Palfrey, Thomas R. (1989): “A Mathematical Proof of Duverger’s Law”. En Peter Ordeshook (ed.), Models of Strategic Choice in Politics. Ann Arbor: University of Michigan Press.

Persson, T. y G. Tabellini (1992a): “Growth, Distribution and Politics”. En European Economic Review, 36: 593-602.

Persson, T. y G. Tabellini (1992b): “The Politics of 1992: Fiscal Policy and European Integration”. En Review of Economic Studies, 59: 689-701.

Persson, T. y G. Tabellini (1994): “Is Inequality Harmful for Growth?”. The American Economic Review. 84 (3): 600-621.

Persson, T. y G. Tabellini (1995): "Double-edged Incentives: Institutions and Policy Coordination”. En G. Grossman y K. Rogoff (eds.), Handbook of International Economics, Vol. 3. Amsterdam: North-Holland.

Persson, T. y G. Tabellini (1996): "Monetary Cohabitation in Europe”. En American Economic Review Papers and Proceedings, 86: 111-116.

Persson, T. (1998): “Economic Policy and Special Interest Politics”. En Economic Journal, 108: 310-327.

Persson, T., G. Roland y G. Tabellini (1998): “Towards Micropolitical Foundations of Public Finance”. En European Economic Review, 42: 685-694.

Persson, T. y G. Tabellini (1999): "Political Economics and Macroeconomics”. En J. Tailor y M. Woodford (eds.), Handbook of Macroeconomics. Amsterdam: North-Holland.

Piketty, T. (1995): “Social Mobility and Redistributive Politics”. En European Economic Review, 43: 791-800.

Plott, Charles (1967): “A Notion of Equilibrium and Its Possibilities Under Majority Rule”. En American Economic Review, 57: 787-806.

Popkin, S. (1979): The Rational Peasant. Berkeley y Los Angeles: University of California Press.

Posner, R. (1980): "A Theory of Primitive Society with Special Reference to the Law”. En Journal of Law and Economics, 23: 1-52.

Posner, Richard (1981): The Economics of Justice. Cambridge Mass: Harvard University Press.

Powell, Robert (1991): “Absolute and Relative Gains in International Relations Theory”. En American Political Science Review, 85: 1303-1320.

Przeworski, Adam y John Sprague (1986): Paper Stones: A History of Electoral Socialism. Chicago: University of Chicago Press. 
Przeworski, Adam (1991): Democracy and the Market: Political and Economic Reforms in Eastern Europe and Latin America. New York: Cambridge University Press. [Existe traducción al castellano en Cambridge University Press.]

Putnam, Robert D. (1988): "Diplomacy and Domestic Politics: The Logic of TwoLevel Games”. En International Organization, 42: 427-460.

Ray, Debraj (1998): Development Economics. Princeton: Princeton University Press. [Existe traducción al castellano en Antoni Bosh.]

Riker, William (1980): "Implications from the Disequilibrium of Majority Rule for the Study of Institutions”. En American Political Science Review, 75: 432-447.

Riker, William (1982): Liberalism Against Populism: A Confrontation Between the Theory of Democracy and the Theory of Social Choice. Illinois: Waveland Press.

Riker, William (1990): “Political Science and Rational Choice”. En J. Alt y K. Shepsle (eds.), Perspectives on Positive Political Economy. Cambridge: Cambridge University Press.

Roberts, K. (1977): “Voting Over Income Tax Schedules”. En Journal of Public Economics, 8: 329-340.

Rodrik, D. (1995): “Political Economy of Trade Policy”. En G. Grossman y K. Rogoff (eds.), Handbook of International Economics, Vol. 3. Amsterdam: North-Holland.

Rodrik, D. y T. van Ypersele (1999): "Capital Mobility, Distributive Conflict and International Tax Consideration”. En Working Paper 7150, National Bureau of Economic Research, Cambridge.

Roemer, J. y Woojin L. (1999): Inequality and Redistribution Revisited. En Economics Letters, 65 (3): 339-346.

Roemer, John (2001): Political Competition: Theory and Application. Cambridge: Harvard University Press.

Rogowski, Ronald (1983): “Structure, Growth and Power: Three Rationalist Accounts”. En International Organization, 37, 4: 713-739.

Romer, T. (1975): "Individual Welfare, Majority Voting and the Properties of a Linear Income Tax”. En Journal of Public Economics, 7: 163-168.

Romer, Thomas y Howard Rosenthal (1978): "Political Resource Allocation, Controlled Agendas, and the Statu Quo”. En Public Choice, 33: 27-44.

Russell, Clifford S. y Norman K. Nicholson (eds.) (1981): Public Choice and Rural Development. Washington, D.C.: Resources for the Future.

Ruttan, Vernon W. (1979a): "Induced Innovation and Agricultural Development”. En Food Policy, 2: 196-216.

Ruttan, Vernon W. (1979b): “Induced Institutional Innovation”. En Agricultural Economic Research, 31: 32-35.

Ruttan, Vernon W. (1980): "Bureaucratic Productivity: The Case of Agricultural Research”. En Public Choice, 35: 529-547.

Saint-Paul, G. y T. Verdier (1993): “Education, Democracy and Growth”. En Journal of Development Economics, 42: 399-407.

Saint-Paul, G. (1999): “The Political Economy of Employment Protection”. Mimeo, Universitad Ponpeu Fabra, Barcelona.

Shepsle, Kenneth (1979): "Institutional Arrangements and Equilibrium in Multidimensional Voting Models”. En American Journal of Political Science, 23: 27-59. 
Shepsle, Kenneth (1986): "Institutional Equilibrium and Equilibrium Institutions". En Herbert Weisberg (ed.), The Science of Politics. New York: Agathon: 51-82.

Shepsle, Kenneth y Barry Weingast (1987): “The Institutional Foundations of Committee Power”. En American Political Science Review, 81: 85-104.

Shepsle, Kenneth (1989): "Studying Institutions: Some Lessons from the Rational Choice Approach”. En Journal of Theoretical Politics, 1: 131-149.

Shepsle, Kenneth y Ronald Cohen (1990): "Multiparty Competition, Entry and Entry Deterrance in Spatial Models of Elections”. En James Enelow y Melvin Hinich (eds.), Advances in the Spatial Theory of Voting. Cambridge: Cambridge University Press.

Shepsle, Kenneth y Weingast (1994): "Positive Theories of Congressional Institutions”. En Legislative Studies Quarterly, 19: 149-80.

Shoefield, Norman J. (1997): "Multiparty Electoral Politics". En Dennis C. Muller (ed.), Perspectives on Public Choice. Cambridge: Cambridge University Press.

Shofield, Norman J. (2003): "Power, Prosperity and Social Choice: A Review". En Public Choice and Welfare, 20: 85-118.

Shugart, Matthew Soberg y John Carey (1992): Presidents and Assemblies: Constitutional Designs and Electoral Dynamics. Cambridge: Cambridge University Press.

Snidal, Duncan (1985): “The Game Theory of International Relations”. En World Politics, 38 (25): 32-36.

Snyder, James M. (1990): "Resource Allocation in Multiparty Elections”. En American Journal of Political Science, 34: 59-73.

Staiger, R. (1995): "International Rules and Institutions for Cooperative Trade Policy”. En G. M. Grossman y Rogoff (ed.), Handbook of International Economics, Vol. 3. Amsterdam u.a.: North-Holland, 1995, pp. 1495-1551.

Stiglitz, Joseph E. (1986): “The New Development Economics”. En World Development, 14, 2: 257-265.

Stokes, S. C. (1999): "Political Parties and Democracy”. En Annual Reviews of Political Science, 2: 243-267.

Stokes, S. C. (2001): "Mandates and Democracy: Neoliberalism by Surprise in Latin America”. New York: Cambridge University Press, 2001,

Sturzenegger, F. y M. Tommasi (1998): The Political Economy of Reform. Cambridge: MIT Press.

Svensson, J. (1996): "Collusion and Interest Groups: Foreign Aid and Rent Dissipation”. Mimeo, The World Bank, Washington, D.C.

Svensson, J. (1997): "The Control of Public Policy: Electoral Competition, Polarization and Primary Elections”. Mimeo, The World Bank, Washington, D.C.

Svensson, J. (1999): “Democracy, Government Spending and Growth”. Mimeo, The World Bank, Washington, D.C.

Svensson, Lars (1999): “Monetary Policy Issues for the Eurosystem”. Discussion Paper $\mathrm{N}^{\circ}$ 2197, Centre of Economic Policy Research, Londres.

Taagapera, Rein y Matthew Soberg Shugart (1989): Seats and Votes. New Heaven: Yale University Press.

Tabellini, G. (1990): "Domestic Politics and the International Coordination of Fiscal Policies”. En Journal of International Economics, 28: 245-265.

Tabellini, G. y A. Alesina (1990): "Voting on the Budget Deficit”. En American Economic Review, 80: 37-39. 
Tesfatsion, Leigh (2001): Agent-based Computational Economics: A Brief Guide to the Literature”. En J. Michie (ed.), Reader's Guide to the Social Sciences, volume 1. London: Fitzroy-Dearborn.

Toye, John (1993): “Is There a New Political Economy of Development?” En C. Colclough y J. Manor (eds.), States or Markets? Neo-liberalism and the Development Policy Debate, Oxford: Clarendon Press.

Tsebelis, George (1990): Nested Games. Berkeley: University of California Press.

Tsebelis, George (2002): Veto Players: How Political Institutions Work. Princeton: Princeton University Press.

Tullock, Gordon (1981): “Why So Much Stability?”. En Public Choice, 37: 189-202.

Von Neumann, John y Oskar Morgenstern (1944): Theory of Games and Economic Behaviour. Princeton, NJ: Princeton University Press.

Valdini, Melody (2005): “Candidate Gender as an Information Shortcut: A Cross-National Analysis of the Effects of Political Enviroments”. En Working Paper, University of California, San Diego.

Vriend, Nicolas (2002): “Introduction”. En Computational Economics (Special Issue on Evolutionary Processes in Economics) 19: 1-4.

Wagner, Harrison (1983): “The Theory of Games and the Problem of International Cooperation”. En American Political Science Review, 77: 330-346.

Wagner, Harrison (1986): "The Theory of Games and the Balance of Powers”. En World Politics, 38: 546-576.

Wagner, Harrison (1991): "Nuclear Deterrence, Counterforce Strategies and the Incentive to Strike First”. En American Political Science Review, 85: 727-750.

Wagner, Harrison (2001): “Who's Afraid of Rational Choice”. Mimeo, University of Texas at Austin, Government Department.

Wallerstein, Michael (1989): “Union Organization in Advanced Industrial Democracies”. En American Political Science Review, 83: 481-501.

Wallerstein, Michael (1990): “Centralized Bargaining and Wage Restraint”. En American Journal of Political Science, 34: 982-1004.

Weingast, Barry y William Marshall (1988): “The Industrial Organization of Congress”. En Journal of Political Economy, 96, 1: 132-166.

Weingast, Barry (1997): "Formal Theory and Comparative Politics". En APSA-CP: News Letter of the APSA Organized Section of Comparative Politics, 8.

Weyland, Kurt (2002): "Limitations of Rational-Choice Institutionalism for the Study of Latin American Politics”. En Studies in Comparative International Development, 37, 1: 57-85.

Wittman, Donald (1973): "Parties as Utility Maximizers". En American Political Science Review, 67: 490-498.

Wittman, Donald (1983): “Candidate Motivation: A Synthesis of Alternative Theories”. En American Political Science Review, 77: 142-157. 